\title{
Presentación
}

\section{Reformas financieras en El Salvador}

Los eventos financieros del año 1997 en El Salvador pusieron en evidencia la necesidad de hacer reformas institucionales profundas en las instituciones encargadas de velar por el desartollo de un sistema financiero sano. Dichas reformas institucionales, como sería la independencia del Banco Central, requieren de un consenso político amplio.

En este contexto, la Agencia de Estados Unidos para el Desarrollo Intemacional (USAID) ha tratado de desarrollar este consenso mediante seminarios, publicaciones y asesorías a las instituciones relacionadas con este tipo de reformas (Banco Central de Reserva, Superintendencia del Sistema Financiero, Superintendencia de Pensiones y la Superintendencia de Valores), así como a la Comisión Especial de Investigaciones Financieras de la Asamblea Legislativa, ya que este tipo de reformas requieren de su aprobación.

En este proceso, la Agencia de Estados Unidos para el Desarrollo Internacional contó con la contribución de prestigiosos especialistas en este campo, como el Profesor Alberto Alesina, de la Universidad de Harvard, así como de otros académicos y profesionales, como el Profesor Andrés Velasco, de la Universidad de New York, y de Michael Reddell del Banco de Reserva de Nueva Zelandia, quien hizo una importante contribución al analizar el modelo de Nueva Zelandia como un caso práctico de un banco central independiente y las posibilidades de aplicar dicho modelo en El Salvador.

Adicionalmente, la USAID tradujo una serie de arlículos publicados en revistas internacionales sobre el tema "Independencia del Banco Central", los cuales se publicarán en español en esta revista con el fin de lograr una mayor difusión en nuestro país de eslos aportes que seguramente contribuirán al debate 
económico nacional. Para este número se seleccionaron los siguientes artículos: "Independencia del Banco Central en El Salvador", de Alberto Alesina. Este documento se elaboró para la Agencia de Estados Unidos para el Desarrollo Internacional, en julio de 1997; "La Independencia del Banco Central y el desempeño macroeconómico: algunas evidencias comparativas, Journal of Money, Credit and Banking, Vol. 25, 2, mayo, 1993. Sucesivamente se irán publicando los demás artículos de la serie. 